\title{
Analisis Kinerja Berbasis Balanced Scorecard pada KSP TEB Artha Mulia yang Menerapkan Financial Technology
}

\author{
Komang Desi Adi Pratiwi ${ }^{1}$ \\ I Nyoman Wijana Asmara Putra ${ }^{2}$ \\ 1,2 Fakultas Ekonomi dan Bisnis Universitas Udayana (Unud), Bali, Indonesia \\ e-mail: deshiadii@gmail.com
}

\begin{abstract}
ABSTRAK
Penelitian ini bertujuan untuk mengetahui dan menganalisis kinerja koperasi yang telah menerapkan financial technology yaitu KSP TEB Artha Mulia dengan menggunakan balanced scorecard. Sampel ditentukan dengan metode probability sampling untuk pelanggan dan non-probability sampling untuk karyawan. Hasil penelitian menunjukkan kinerja dari perspektif keuangan dilihat dari rasio likuiditas dan rasio kecukupan modal sendiri sudah memenuhi standar ideal yang ditetapkan dan pada rasio profitabilitas belum mencapai standar ideal yang ditetapkan. Kinerja perspektif pelanggan dan perspektif proses bisnis internal menunjukkan hasil yang baik. Kinerja perspektif pembelajaran dan pertumbuhan dilihat dari tingkat kepuasan karyawan dan tingkat produktivitas karyawan adalah baik, namun pada tingkat retensi karyawan menunjukkan hasil yang belum tergolong baik. Penelitian ini diharapkan dapat digunakan sebagai acuan bagi koperasi untuk merencanakan strategi yang tepat di masa mendatang.

Kata kunci: Kinerja; balanced scorecard; financial technology
\end{abstract}

\begin{abstract}
This study aims to determine and analyze the performance of cooperativ that has implemented financial technology, KSP TEB Artha Mulia, by using balanced scorecard. The sample is determined by the probability sampling for customers and non-probability sampling for employees. The results of the study show that the performance from financial perspective seen from the liquidity ratio and the capital adequacy ratio has reached the ideal standards and the profitability ratio has not reached the ideal standards. The performance of the customer perspective and the internal business process perspective show good results. The performance of learning and growth perspectives seen from the level of employee satisfaction and the level of employee productivity is good, but the employee retention rate shows results that have not been classified as good. This research is expected to be used as a reference for cooperatives to plan the right strategy in the future.
\end{abstract}

Keywords: Performance; balanced scorecard; financial technology

\section{PENDAHULUAN}

Informasi mengenai kinerja dapat memberikan gambaran mengenai keberlangsungan hidup perusahaan. Kinerja menurut Karma dkk. (2017) merupakan gambaran tingkat pencapaian pelaksanaan program kegiatan atau kebijakan dalam mewujudkan tujuan, visi, dan misi organisasi yang dituangkan 
melalui perencanaan strategis. Pengukuran kinerja selama ini lebih banyak ditinjau dari aspek keuangan saja (Hery, 2017: 46). Data yang dibutuhkan untuk pengukuran tersebut bisa langsung diperoleh melalui laporan keuangan. Sistem pengukuran kinerja harus mampu menilai perkembangan dan pertumbuhan perusahaan dalam ukuran keuangan dan non keuangan (Zizlavsky, 2014). Kaplan \& Norton (1996) memperkenalkan sistem pengukuran kinerja yang dinamakan balanced scorecard. Konsep dalam balanced scorecard digunakan untuk mengetahui hubungan sebab akibat antara aspek keuangan dan non keuangan dalam perusahaan (Abofaied, 2017).

Balanced scorecard merupakan suatu konsep memiliki tujuan untuk menerjemahkan strategi sebagai langkah-langkah yang akan menghubungkan visi dan misi organisasi menjadi satu keutuhan (Stefanovska dan Soklevski, 2014). Balanced scorecard memastikan bahwa operasi perusahaan dapat sejalan dengan misi dan strateginya (Ridwan et al., 2013). Balanced scorecard memiliki kemampuan untuk menyediakan kerangka kerja untuk penilaian kinerja secara keseluruhan (Ibrahim dan Murtala, 2015). Balanced scorecard dikembangkan untuk melengkapi kekurangan dari pengukuran kinerja tradisional yang hanya mengutamakan aspek keuangan saja (Pebrianata dan Putri, 2014).

Ningsih (2014) menyatakan bahwa teknologi informasi memiliki pengaruh positif dan signifikan terhadap kinerja organisasi. Astuti dan Dharmadiaksa (2014) pun menyatakan bahwa pemanfaatan teknologi informasi berpengaruh positif signifikan terhadap kinerja karyawan. Alannita dan Suaryana (2014) juga menyatakan bahwa kecanggihan teknologi berpengaruh positif pada kinerja 
individu. Perkembangan teknologi informasi ini telah merambah ke berbagai sektor, salah satunya adalah sektor keuangan. Menurut Prawirasasra (2018), financial technology menghasilkan pendapatan melalui penyediaan layanan keuangan berbasis teknologi. Adanya financial technology ini dapat membantu meningkatkan keuangan pada usaha mikro kecil dan menengah di masyarakat (Muzdalifa dkk., 2018).

Koperasi sebagai salah satu organisasi ekonomi tidak lepas dari keberadaan financial technology. Koperasi dituntut untuk terus berupaya meningkatkan kinerjanya agar dapat beroperasi dengan baik dan efisien, karena dunia usaha semakin kompetitif di tengah pesatnya perkembangan teknologi (Surya, 2014). Salah satu koperasi yang telah menerapkan financial technology yaitu KSP TEB Artha Mulia. Sejak tahun 2015, KSP TEB Artha Mulia telah mengembangkan layanan keuangan digital berbasis teknologi internet yang dinamakan SAKTI yaitu Sistem Akuntansi Koperasi Basis Teknologi Internet. Pengembangan SAKTI ini ditujukan untuk memaksimalkan layanan kepada anggota melalui inovasi dalam pelayanan dan pengembangan yang disesuaikan dengan kebutuhan anggota.

Penilaian kinerja rutin dilaksanakan oleh KSP TEB Artha Mulia. Penilaian kinerja koperasi ini didasarkan pada Peraturan Deputi Bidang Pengawasan Kementerian Koperasi dan Usaha Kecil dan Menengah Republik Indonesia Nomor 06/Per/Dep/IV/2016 Tentang Pedoman Penilaian Kesehatan Koperasi Simpan Pinjam dan Unit Simpan Pinjam. Ruang lingkup penilaian pada peraturan ini sebagian besar merupakan aspek keuangan, sehingga dibutuhkan suatu 
penilaian komperehensif yang mampu menilai kinerja koperasi ini dari aspek non keuangan. Penilaian pada aspek keuangan dan non keuangan dapat diukur menggunakan balanced scorecard.

Rumusan masalah dalam penelitian ini adalah bagaimana kinerja dari perspektif keuangan, perspektif pelanggan, perspektif proses bisnis internal, dan perspektif pembelajaran dan pertumbuhan pada KSP TEB Artha Mulia. Berdasarkan rumusan masalah tersebut maka tujuan penelitian ini adalah untuk mengetahui dan menganalisis kinerja dari perspektif keuangan, perspektif pelanggan, perspektif proses bisnis internal, perspektif pembelajaran dan pertumbuhan pada KSP TEB Artha Mulia.

Hasil penelitian ini diharapkan mampu memberikan kontribusi pada dunia akademis sebagai bahan kajian terhadap perkembangan ilmu pengetahuan, menambah wawasan khususnya mengenai kinerja berbasis balanced scorecard pada koperasi dengan penerapan financial technology, serta menjadi referensi untuk pengembangan penelitian di masa yang akan datang. Hasil penelitian ini juga diharapkan dapat digunakan sebagai pengetahuan dan masukan bagi KSP TEB Artha Mulia untuk melihat kinerja koperasinya.

Kinerja didefinisikan sebagai kondisi yang harus diketahui dan diinformasikan kepada pihak tertentu untuk mengetahui tingkat pencapaian hasil perusahaan serta dampak positif fan negatif dari suatu kebijakan operasional (Rismawati \& Mattalata, 2018). Pengukuran kinerja merupakan unsur yang penting untuk mengetahui tingkat keberhasilan atau pencapaian perusahaan dalam 
mencapai tujuan yang ditetapkan baik tujuan jangka pendek maupun tujuan jangka panjang (Hery, 2017: 48).

Balanced scorecard berasal dari kata balanced (berimbang) yang berarti adanya keseimbangan antara kinerja keuangan dan non keuangan, yang bersifat internal dan eksternal, serta jangka pendek dan jangka panjang, dan scorecard (kartu skor) yaitu kartu yang digunakan untuk mencatat nilai suatu kinerja (Limbu dan Sisdyani, 2016). Balanced scorecard didasarkan pada hubungan sebab dan akibat, aspek keuangan dan non keuangan untuk tujuan jangka panjang (AlHosaini dan Sofian, 2015). Penelitian oleh Sahiti et al., (2016) menunjukkan bahwa balanced scorecard berkontribusi untuk meningkatkan kinerja dan profitabilitas untuk bisnis yang diterapkan. Lesakova dan Dubcova (2016) menyatakan bahwa alasan utama menerapkan metode balanced scorecard adalah untuk memperkuat evaluasi kinerja bisnis dengan ukuran non keuangan.

Balanced scorecard terdiri dari empat perspektif yaitu perspektif keuangan, perspektif pelanggan, perspektif proses bisnis internal, dan perspektif pembelajaran dan pertumbuhan. Perspektif keuangan merupakan ukuran keuangan yang penting dalam memberikan ringkasan mengenai konsekuensi atas keputusan dan tindakan ekonomis yang telah diambil oleh pihak manajemen perusahaan (Utama, 2016: 253). Perspektif pelanggan mengacu pada bagaimana perusahaan dapat menciptakan nilai bagi pelanggan (Kopecka., 2015). Perspektif proses bisnis internal berfokus pada kegiatan yang dilakukan organisasi untuk memuaskan pelanggannya (Giannopoulos et al., 2013). Perspektif pembelajaran dan 
pertumbuhan melibatkan kemampuan dan keterampilan karyawan, teknologi dan iklim perusahaan untuk mendukung strategi perusahaan (Martello et al, 2016).

Financial technology merupakan sektor ekonomi dimana perusahaan menawarkan layanan keuangan yang berbeda dengan menggunakan teknologi baru untuk membuat proses layanan lebih efisien untuk diri mereka sendiri dan lebih nyaman bagi pelanggan (Kalmykova dan Ryabova, 2016). Kolaborasi lintas industri memungkinkan perusahaan tumbuh lebih cepat dengan biaya lebih rendah dibandingkan hanya dengan mengembangkan produk yang inovatif (Teja, 2017). Perkembangan ilmu pengetahuan dan teknologi dan sektor keuangan memiliki pengaruh yang signifikan terhadap pertumbuhan ekonomi negara (Sepehrdoust, 2018). Penelitian oleh Meifang et al. (2018) juga menunjukkan bahwa pengembangan teknologi pembayaran pada industri keuangan tradisional di China memiliki hubungan positif yang signifikan pada kemampuan penciptaan nilai dari industri keuangan tradisional di China dan hubungan ini cenderung tetap pada keadaan stabil dalam jangka panjang.

Pengertian Koperasi sebagaimana diatur dalam Pasal 1 Ayat 1 UndangUndang Nomor 25 Tahun 1992 Tentang Perkoperasian disebutkan bahwa "koperasi adalah badan usaha yang beranggotakan orang-seorang atau badan hukum koperasi dengan melandaskan kegiatannya berdasarkan prinsip koperasi sekaligus sebagai gerakan ekonomi rakyat yang berdasar atas asas kekeluargaan". KSP TEB Artha Mulia merupakan koperasi yang terletak di Jalan Beringin, Banjar Pegending, Desa Dalung, Kecamatan Kuta Utara, Kabupaten Badung, Bali. Koperasi ini juga memiliki kantor cabang yang berlokasi di Panglan, 
Denpasar Timur dan Baturiti. Koperasi ini didirikan pada tanggal 14 Februari 2014 dengan Badan Hukum Nomor 04/BH/XXVII/XI/2014.

\section{METODE PENELITIAN}

Penelitian ini dilakukan pada Koperasi Simpan Pinjam Tri Eka Bina Artha Mulia. Koperasi ini merupakan salah satu koperasi yang telah menerapkan financial technology. Koperasi ini baru berdiri sejak tahun 2014 namun aset yang dimiliki telah mencapai Rp13.476.171.393 di tahun buku 2017.

Populasi dalam penelitian ini adalah anggota KSP TEB Artha Mulia yang berjumlah 1.500 orang dan karyawan KSP TEB Artha Mulia yang berjumlah 20 orang. Metode penentuan sampel untuk jumlah pelanggan dan karyawan berbeda. Metode penentuan sampel untuk pelanggan mengunakan probability sampling dengan menggunakan teknik simple random sampling. Metode penentuan sampel karyawan menggunakan non-probability sampling dengan menggunakan sampling jenuh. Berdasarkan populasi anggota yang ada di KSP TEB Artha Mulia dan metode penentuan sampel yang digunakan oleh peneliti, maka sampel anggota akan diambil secara acak yang jumlahnya dihitung menggunakan rumus Slovin. Perhitungan sampel untuk anggota secara matematis disajikan pada rumus (1).

$$
n=\frac{N}{1+N e^{2}}
$$

Keterangan:

$\mathrm{n}$ = Ukuran sampel

$\mathrm{N}=$ Ukuran populasi

$\mathrm{e}=$ Tingkat kesalahan yang ditoleransi (peneliti menggunakan 10\%) 
Berdasarkan rumus (1), sampel anggota dapat dihitung sebagai berikut.

$n=\frac{1.500}{1+(1.500)(0,1)^{2}}$

$n=\frac{1.500}{16}$

$n=93,75$

Maka jumlah sampel anggota koperasi yang dibutuhkan yaitu 94 orang (dibulatkan). Berdasarkan populasi karyawan yang ada di KSP TEB Artha Mulia dan metode penentuan sampel karyawan yang digunakan oleh peneliti, maka sampel karyawan yang diambil berjumlah sama dengan populasi karyawan yaitu berjumlah 20 orang.

Metode pengumpulan data yang digunakan dalam penelitian ini adalah dokumentasi dan kuesioner. Dokumentasi digunakan untuk mengumpulkan data terkait dengan sejarah, visi misi, produk yang dimiliki, struktur organisasi, rasio pada perspektif keuangan, tingkat pertumbuhan anggota pada perspektif pelanggan, kapasitas infrastruktur dan tingkat pertumbuhan inovasi pada perspektif proses bisnis internal, serta tingkat retensi karyawan dan tingkat produktivitas karyawan pada perspektif pembelajaran dan pertumbuhan. Kuesioner digunakan untuk mengumpulkan data terkait tingkat kepuasan pelanggan pada perspektif pelanggan dan tingkat kepuasan karyawan pada perspektif pembelajaran dan pertumbuhan.

Jenis data yang digunakan dalam penelitian ini adalah data kuantitatif dan data kualitatif. Data kuantitatif dalam penelitian ini yaitu data yang disajikan di laporan keuangan KSP TEB Artha Mulia, data mengenai jumlah anggota koperasi, jumlah produk baru dan jumlah keseluruhan produk KSP TEB Artha Mulia, dan data mengenai jumlah karyawan. Data kualitatif dalam penelitian ini 
yaitu data mengenai sejarah, data mengenai visi misi, data mengenai layanan yang diberikan, data mengenai struktur organisasi, jawaban responden pada kuesioner tingkat kepuasan pelanggan dan tingkat kepuasan karyawan.

Sumber data yang digunakan dalam penelitian ini adalah data primer dan data sekunder. Data primer dalam penelitian ini adalah jawaban responden atas pertanyaan yang terdapat dalam kuesioner yang disebarkan ke anggota dan karyawan KSP TEB Artha Mulia. Data sekunder dalam penelitian ini yaitu data sejarah, data visi misi, data produk yang dijual, data struktur organisasi, data laporan keuangan, data jumlah anggota, data jumlah produk baru, data jumlah total produk dan data jumlah karyawan KSP TEB Artha Mulia.

Metode pengumpulan data dalam penelitian ini salah satunya dilakukan dengan menggunakan kuesioner. Pengujian instrumen penelitian yang dilakukan pada kuesioner adalah pengujian validitas data dan reliabilitas data. Untuk menguji apakah masing-masing pertanyaan dari kuesioner valid atau tidak, dapat dilihat pada hasil output SPSS Cronbach's Alpha di kolom Correlated Item Total Correlation. Syarat minimum suatu kuesioner agar dapat dikatakan valid adalah jika nilai Correlated Item-Total Correlation mempunyai nilai lebih dari atau sama dengan 0,30 (Sari \& Putri, 2014). Peneliti mengukur reliabelnya suatu variabel dalam pengujian ini dengan cara melihat Cronbach's Alpha dengan signifikansi yang digunakan lebih besar dari 0,70 suatu variabel dikatakan reliabel jika memberikan nilai Cronbach's Alpha > 0,70 (Ghozali, 2016: 48).

Kinerja perspektif keuangan dalam penelitian ini diukur menggunakan 3 (tiga) rasio yaitu rasio likuiditas, rasio kecukupan modal sendiri dan rasio 
profitabilitas. Penilaian terhadap rasio likuiditas diukur dengan rasio kas. Rasio kas digunakan untuk mengukur kemampuan koperasi memenuhi kewajibannya yang segera jatuh tempo dengan kas yang dimiliki (Wiagustini, 2014: 88). Rasio kas ideal yang ditetapkan dalam Peraturan Deputi Bidang Pengawasan Kementerian Koperasi dan Usaha Kecil dan Menengah Republik Indonesia Nomor 06/Per/Dep/IV/2016 Tentang Pedoman Penilaian Kesehatan Koperasi Simpan Pinjam dan Unit Simpan Pinjam Koperasi adalah sebesar 10 - 15 persen. Secara matematis rasio ini dihitung dengan rumus sebagai berikut.

$$
\text { Rasio kas }=\frac{\text { Kas }+ \text { Bank }}{\text { Kewajiban lancar }} \times 100 \%
$$

Rasio kecukupan modal sendiri adalah perbandingan modal sendiri tertimbang dengan aktiva tertimbang menurut risiko (ATMR) dikalikan dengan 100 persen. Rasio kecukupan modal sendiri ideal yang ditetapkan dalam Peraturan Deputi Bidang Pengawasan Kementerian Koperasi dan Usaha Kecil dan Menengah Republik Indonesia Nomor 06/Per/Dep/IV/2016 Tentang Pedoman Penilaian Kesehatan Koperasi Simpan Pinjam dan Unit Simpan Pinjam Koperasi adalah lebih besar dari 8 persen. Secara matematis rasio kecukupan modal sendiri dihitung dengan rumus sebagai berikut.

$$
\text { Rasio kecukupan modal sendiri }=\frac{\text { Modal sendiri tertimbang }}{A T M R} \times 100 \%
$$

Penilaian terhadap rasio profitabilitas diukur dengan rasio rentabilitas modal sendiri. Rasio rentabilitas modal sendiri ideal yang ditetapkan dalam Peraturan Deputi Bidang Pengawasan Kementerian Koperasi dan Usaha Kecil dan Menengah Republik Indonesia Nomor 06/Per/Dep/IV/2016 Tentang Pedoman Penilaian Kesehatan Koperasi Simpan Pinjam dan Unit Simpan Pinjam Koperasi 
adalah lebih besar atau sama dengan 5 persen. Secara matematis rasio ini dihitung dengan rasio sebagai berikut.

$$
\text { Rasio rentabilitas modal sendiri }=\frac{\text { SHU bagian anggota }}{\text { Total aset }} \times 100 \%
$$

Kinerja perspektif pelanggan dalam penelitian ini diukur dengan menggunakan tingkat kepuasan pelanggan dan tingkat pertumbuhan anggota. Tingkat kepuasan pelanggan yaitu pernyataan kepuasan konsumen yang menguraikan mengenai kualitas jasa pelayanan yang diperoleh oleh anggota (Indranatha dan Suryanawa, 2013). Setiap indikator kepuasan pelanggan diukur menggunakan instrumen yang diadopsi dari penelitian Pika dan Dharmadiaksa (2018). Tingkat kepuasan pelanggan diukur dengan menganalisis jawaban atas pertanyaan dalam kuesioner tingkat kepuasan pelanggan. Penilaian dilakukan dengan melihat pernyataan positif dan negatif. Menurut Putri dan Wirasedana (2015), ketika proporsi pernyataan positif lebih tinggi dari 60 persen, maka kinerja dari perspektif ini digolongkan pada kualifikasi kinerja baik. Jika responden yang memberikan pernyataan positif berada pada rentangan $0-59$ persen, maka digolongkan pada kualifikasi kinerja buruk. Pada penelitian ini, jawaban sangat setuju dan setuju termasuk kategori pernyataan positif sedangkan jawaban kurang setuju dan tidak setuju termasuk kategori pernyataan negatif.

Tingkat pertumbuhan anggota yaitu kemampuan koperasi dalam menarik anggota baru yang dihitung dengan membandingkan jumlah pelanggan tahun sekarang dikurangi jumlah pelanggan tahun lalu dibagi dengan jumlah pelanggan tahun lalu (Indranatha dan Suryanawa, 2013). Apabila jumlah anggota mengalami peningkatan maka diklasifikasikan pada kinerja yang baik, sedangkan jumlah 
anggota yang mengalami penurunan menunjukkan kinerja yang buruk (Indranatha dan Suryanawa, 2013). Secara matematis dirumuskan sebagai berikut.

$\begin{aligned} & \text { Tingkat pertumbuhan } \\ & \text { anggota }\end{aligned}=\frac{\text { Jml. anggota sekarang-jml. anggota lalu }}{\text { Jumlah anggota lalu }} \times 100 \% \ldots$

Perspektif proses bisnis internal diukur dengan menggunakan kapasitas infrastruktur dan tingkat pertumbuhan inovasi. Kapasitas infrastruktur diukur dengan melihat tingkat penambahan nilai sarana dan prasarana yang mendukung operasional yaitu pertumbuhan jumlah aset tetap per tahunnya (Pika dan Dharmadiaksa, 2018). Jika terjadi penambahan aset tetap maka digolongkan pada kualifikasi peningkatan mutu pelayanan, jika terjadi penurunan aset tetap maka digolongkan pada kualifikasi penurunan mutu pelayanan (Pika dan Dharmadiaksa, 2018).

Tingkat pertumbuhan inovasi merupakan jumlah produk baru dibandingkan dengan jumlah seluruh produk yang dimiliki (Pika dan Dharmadiaksa, 2018). Apabila jumlah produk mengalami peningkatan maka diklasifikasikan pada kinerja yang baik (Pika dan Dharmadiaksa, 2018). Secara matematis dihitung menggunakan rumus sebagai berikut.

Tingkat pertumbuhan inovasi $=\frac{\text { Jumlah produk baru }}{\text { Jumlah seluruh produk }} \times 100 \%$

Tolak ukur yang digunakan untuk mengukur perspektif pembelajaran dan pertumbuhan yaitu tingkat retensi karyawan, tingkat produktivitas karyawan dan tingkat kepuasan karyawan. Tingkat retensi karyawan yaitu persentase perbandingan antara jumlah karyawan yang keluar dengan jumlah karyawan pada periode tahun yang bersangkutan (Indranatha dan Suryanawa, 2013). Apabila 
tidak terdapat karyawan yang keluar maka diklasifikasikan pada kinerja yang baik (Indranatha dan Suryanawa, 2013). Secara matematis dirumuskan sebagai berikut.

Tingkat retensi karyawan $=\frac{\text { Jumlah karyawan yang keluar }}{\text { Jumlah karyawan }} \times 100 \% \ldots$ (7)

Tingkat produktivitas karyawan yaitu perbandingan antara jumlah pendapatan dengan jumlah karyawan pada periode tahun yang bersangkutan (Indranatha dan Suryanawa, 2013). Tingkat produktivitas karyawan diukur dengan membandingkan jumlah pendapatan dengan jumlah karyawan pada periode tahun yang bersangkutan dengan tahun sebelumnya. Apabila persentase menunjukkan angka yang positif yang menandakan adanya peningkatan maka diklasifikasikan pada kinerja yang baik (Indranatha dan Suryanawa, 2013). Secara matematis dirumuskan sebagai berikut.

Tingkat produktivitas karyawan $=\frac{\text { Jumlah pendapatan }}{\text { Jumlah karyawan }} \times 100 \%$

Tingkat kepuasan karyawan yaitu pernyataan kepuasan karyawan yang menguraikan kondisi lingkungan kerjanya (Indranatha dan Suryanawa, 2013). Setiap indikator kepuasan pelanggan diukur menggunakan instrumen yang diadopsi dari penelitian Pika dan Dharmadiaksa (2018). Penilaian dilakukan dengan melihat pernyataan positif dan negatif yang diberikan responden. Menurut Putri dan Wirasedana (2015) ketika proporsi lebih dari 60 persen, maka kinerja dari perspektif ini digolongkan pada kinerja baik, jika responden yang memberikan pernyataan positif berada pada rentangan $0-59$ persen maka KSP TEB Artha Mulia digolongkan pada kinerja buruk. 


\section{HASIL DAN PEMBAHASAN}

Peneliti telah melakukan penyebaran kuesioner kepada anggota dan karyawan KSP TEB Artha Mulia, dan diketahui bahwa banyaknya kuesioner yang disebar kepada anggota sebanyak 94 kuesioner, yang kembali sebanyak 94 kuesioner dan terisi lengkap. Kuesioner yang disebar kepada karyawan adalah sebanyak 20 kuesioner, yang kembali sebanyak 20 kuesioner dan terisi lengkap.

Tabel 1.

Karakteristik Responden pada Perspektif Pelanggan

\begin{tabular}{|c|c|c|c|}
\hline \multirow{2}{*}{ No. } & \multirow{2}{*}{ Karakteristik Responden } & \multicolumn{2}{|c|}{ Jumlah } \\
\hline & & (orang) & Persentase $(\%)$ \\
\hline \multirow[t]{4}{*}{1} & Jenis Kelamin & & \\
\hline & Pria & 39 & 41,49 \\
\hline & Wanita & 55 & 58,51 \\
\hline & Total & 94 & 100,00 \\
\hline \multirow[t]{10}{*}{2} & Umur & & \\
\hline & $15-20$ & 12 & 12,77 \\
\hline & $21-26$ & 16 & 17,02 \\
\hline & $27-32$ & 12 & 12,77 \\
\hline & $33-38$ & 8 & 8,51 \\
\hline & $39-44$ & 20 & 21,28 \\
\hline & $45-50$ & 12 & 12,77 \\
\hline & $51-56$ & 9 & 9,57 \\
\hline & $57-62$ & 5 & 5,32 \\
\hline & Total & 94 & 100,00 \\
\hline \multirow[t]{4}{*}{3} & Penggunaan Layanan Koperasi & & \\
\hline & Menyimpan dana & 94 & 100,00 \\
\hline & Meminjam dana & 26 & 27,66 \\
\hline & Penggunaan layanan financial technology & 37 & 39,36 \\
\hline
\end{tabular}

Berdasarkan data pada Tabel 1 dapat diketahui bahwa responden dari perspektif pelanggan didominasi oleh wanita dengan 58,51 persen. Responden dari aspek umur didominasi 39 - 44 tahun dengan 21,38 persen. Responden dari aspek penggunaan layanan koperasi, 100 persen responden melakukan simpanan pada koperasi, 27,66 persen anggota melakukan pinjaman pada koperasi dan 39,36 persen anggota menggunakan layanan financial technology yang disediakan oleh koperasi. 
Tabel 2.

Karakteristik Responden pada Perspektif Pembelajaran dan Pertumbuhan

\begin{tabular}{cccc}
\hline \multirow{2}{*}{ No. } & \multirow{2}{*}{ Karakteristik Responden } & \multicolumn{2}{c}{ Jumlah } \\
\cline { 3 - 4 } & & (orang) & Presentase $(\%)$ \\
\hline 1 & Jenis Kelamin & 5 & 25,00 \\
& Pria & 15 & 75,00 \\
Wanita & 20 & 100,00 \\
\multirow{4}{*}{2} & Total & & \\
& Umur (tahun) & 15 & 75,00 \\
& $18-25$ & 1 & 5,00 \\
& $26-33$ & 0 & 0,00 \\
& $34-41$ & 2 & 10,00 \\
& $42-49$ & 2 & 10,00 \\
& $50-57$ & 20 & 100,00 \\
4 & Total & & \\
& Lama Bekerja (bulan) & 14 & 70,00 \\
& $1-12$ & 0 & 0,00 \\
& $13-24$ & 4 & 20,00 \\
& $25-36$ & 1 & 5,00 \\
& $37-48$ & 1 & 5,00 \\
& $49-60$ & 20 & 100,00 \\
& Total & &
\end{tabular}

Sumber: Data diolah, 2019

Berdasarkan data pada Tabel 2 dapat diketahui bahwa responden pada perspektif pembelajaran dan pertumbuhan didominasi oleh wanita dengan persentase 75,00 persen sedangkan pria dengan 25,00 persen. Responden dari aspek umur didominasi 18 - 25 tahun dengan persentase 75,00 persen. Responden dari aspek lama bekerja didominasi 1 - 12 bulan dengan persentase 70,00 persen.

Metode pengumpulan data dalam penelitian ini salah satunya menggunakan kuesioner. Pengujian instrumen penelitian yang dilakukan pada kuesioner adalah uji validitas data dan uji reliabilitas data. Syarat minimum suatu kuesioner agar dapat dikatakan valid adalah jika nilai Correlated Item-Total Correlation bernilai lebih dari atau sama dengan 0,30 dan dapat dikatakan reliabel jika memberikan nilai Cronbach's Alpha lebih besar dari 0,70. Berdasarkan uji SPSS, maka didapatkan nilai Correlated Item-Total Correlation masing-masing pertanyaan. 
Rincian rekapitulasi hasil uji validitas pada perspektif pelanggan KSP TEB Artha Mulia yang disajikan pada Tabel 3.

Tabel 3.

Rekapitulasi Hasil Uji Validitas Data Responden pada Perspektif Pelanggan

\begin{tabular}{|c|c|c|c|}
\hline No & Atribut - atribut Mutu Jasa & $\begin{array}{l}\text { Correlated } \\
\text { Item-Total } \\
\text { Correlation }\end{array}$ & Keterangan \\
\hline & Reliability (Keandalan) & & \\
\hline 1 & Karyawan koperasi bekerja dengan teliti dan akurat & 0,576 & Valid \\
\hline 2 & $\begin{array}{l}\text { Karyawan koperasi memiliki pengetahuan dan } \\
\text { keterampilan yang baik dalam melayani anggota koperasi } \\
\text { Layanan financial technology (Sakti.link, Sakti Pay atau }\end{array}$ & 0,533 & Valid \\
\hline 3 & $\begin{array}{l}\text { Sakti Apps) memudahkan proses simpan pinjam anggota } \\
\text { koperasi }\end{array}$ & 0,417 & Valid \\
\hline 4 & $\begin{array}{l}\text { Layanan financial technology (Sakti.link, Sakti Pay atau } \\
\text { Sakti Apps) memberikan manfaat bagi anggota koperasi } \\
\text { Responsiveness (Cepat Tanggap) }\end{array}$ & 0,377 & Valid \\
\hline 5 & $\begin{array}{l}\text { Karyawan koperasi bekerja secara cepat dan tanggap } \\
\text { dalam memberikan pelayanan }\end{array}$ & 0,690 & Valid \\
\hline 6 & $\begin{array}{l}\text { Karyawan koperasi menanggapi keluhan nasabah dengan } \\
\text { cepat dan tanggap }\end{array}$ & 0,578 & Valid \\
\hline 7 & $\begin{array}{l}\text { Ketika terjadi gangguan dalam layanan financial } \\
\text { tecnology, karyawan koperasi mampu menangani dengan } \\
\text { cepat } \\
\text { Assurance (Jaminan) }\end{array}$ & 0,630 & Valid \\
\hline 8 & $\begin{array}{l}\text { Karyawan koperasi selalu bersikap ramah dan sopan } \\
\text { dalam melayani anggota koperasi }\end{array}$ & 0,565 & Valid \\
\hline 9 & $\begin{array}{l}\text { Koperasi telah bersikap transparan tentang informasi yang } \\
\text { diperlukan anggota }\end{array}$ & 0,550 & Valid \\
\hline 10 & $\begin{array}{l}\text { Anggota koperasi merasa aman dalam menggunakan } \\
\text { layanan financial technology (Sakti.link, Sakti Pay atau } \\
\text { Sakti Apps) } \\
\text { Empathy (Empati) }\end{array}$ & 0,508 & Valid \\
\hline 11 & $\begin{array}{l}\text { Karyawan koperasi melayani anggota koperasi dengan } \\
\text { senang hati }\end{array}$ & 0,733 & Valid \\
\hline 12 & $\begin{array}{l}\text { Karyawan koperasi selalu memerhatikan kondisi } \\
\text { anggotanya }\end{array}$ & 0,605 & Valid \\
\hline 13 & $\begin{array}{l}\text { Layanan financial technology (Sakti.link, Sakti Pay atau } \\
\text { Sakti Apps) bisa digunakan oleh setiap anggota } \\
\text { Tangible (Kasat Mata) }\end{array}$ & 0,578 & Valid \\
\hline 14 & Koperasi memiliki fasilitas fisik yang memadai & 0,578 & Valid \\
\hline 15 & Koperasi terletak di lokasi yang strategis & 0,374 & Valid \\
\hline 16 & $\begin{array}{l}\text { Tampilan layanan financial technology (Sakti.link, Sakti } \\
\text { Pay atau Sakti Apps) sudah baik }\end{array}$ & 0,694 & Valid \\
\hline
\end{tabular}

Sumber: Data diolah, 2019

Rincian rekapitulasi hasil uji validitas data responden pada perspektif pembelajaran dan pertumbuhan KSP TEB Artha Mulia yang disajikan pada Tabel 4. 
Tabel 4.

Rekapitulasi Hasil Uji Validitas Data Responden pada Perspektif Pembelajaran dan Pertumbuhan

\begin{tabular}{|c|c|c|c|}
\hline No & Atribut - atribut Mutu Jasa & $\begin{array}{l}\text { Correlated } \\
\text { Item-Total } \\
\text { Correlation } \\
\end{array}$ & Keterangan \\
\hline & Atribut Kepuasan Kerja & & \\
\hline 1 & $\begin{array}{l}\text { Saya merasa puas dengan gaji yang diterima saat ini } \\
\text { dan dapat memenuhi kebutuhan sehari - hari }\end{array}$ & 0,901 & Valid \\
\hline 2 & $\begin{array}{l}\text { Saya merasa puas dengan bonus dan insentif yang } \\
\text { diberikan koperasi }\end{array}$ & 0,818 & Valid \\
\hline 3 & $\begin{array}{l}\text { Saya merasa puas dengan tunjangan kesehatan yang } \\
\text { diberikan koperasi }\end{array}$ & 0,802 & Valid \\
\hline 4 & $\begin{array}{l}\text { Saya merasa puas, karena koperasi memberikan } \\
\text { kepastian kerja pada jabatan saya (jam kerja, deskripsi } \\
\text { pekerjaan dan spesifikasi pekerjaan) }\end{array}$ & 0,776 & Valid \\
\hline 5 & $\begin{array}{l}\text { Saya merasa puas dengan penilaian kinerja karyawan } \\
\text { yang dilakukan koperasi }\end{array}$ & 0,836 & Valid \\
\hline 6 & $\begin{array}{l}\text { Saya merasa puas dengan peraturan penggunaan } \\
\text { fasilitas koperasi }\end{array}$ & 0,718 & Valid \\
\hline 7 & $\begin{array}{l}\text { Saya merasa puas dengan kenyamanan dan kebersihan } \\
\text { tempat kerja saya }\end{array}$ & 0,327 & Valid \\
\hline 8 & $\begin{array}{l}\text { Saya merasa puas dengan tingkat kebisingingan yang } \\
\text { tidak mengganggu kegiatan kerja }\end{array}$ & 0,858 & Valid \\
\hline 9 & $\begin{array}{l}\text { Saya merasa puas dengan penataan interior kantor } \\
\text { koperasi }\end{array}$ & 0,307 & Valid \\
\hline 10 & Hubungan saya erat dengan atasan saya & 0,854 & Valid \\
\hline 11 & $\begin{array}{l}\text { Atasan saya selalu memberikan bimbingan dalam } \\
\text { pekerjaan }\end{array}$ & 0,871 & Valid \\
\hline 12 & Hubungan saya erat dengan rekan kerja & 0,786 & Valid \\
\hline 13 & $\begin{array}{l}\text { Sesama rekan kerja, kami saling membantu dalam hal } \\
\text { pekerjaan }\end{array}$ & 0,756 & Valid \\
\hline 14 & $\begin{array}{l}\text { Saya merasa lebih mudah menggunakan financial } \\
\text { technology dalam melayani anggota }\end{array}$ & 0,616 & Valid \\
\hline 15 & $\begin{array}{l}\text { Saya merasa puas menjadi bagian dari koperasi yang } \\
\text { menerapkan financial technology }\end{array}$ & 0,616 & Valid \\
\hline 16 & $\begin{array}{l}\text { Saya merasa termotivasi dengan adanya promosi } \\
\text { jabatan yang jelas }\end{array}$ & 0,797 & Valid \\
\hline & Atribut Motivasi Kerja & & \\
\hline 17 & $\begin{array}{l}\text { Saya merasa termotivasi dengan adanya perkembangan } \\
\text { karir yang diberikan koperasi }\end{array}$ & 0,674 & Valid \\
\hline 18 & $\begin{array}{l}\text { Saya berupaya memberikan hasil yang terbaik bagi } \\
\text { koperasi }\end{array}$ & 0,814 & Valid \\
\hline 19 & $\begin{array}{l}\text { Saya merasa termotivasi dengan adanya pemberian } \\
\text { bonus dan tunjangan }\end{array}$ & 0,749 & Valid \\
\hline
\end{tabular}


Lanjutan...

\begin{tabular}{|c|c|c|c|}
\hline No & Atribut - atribut Mutu Jasa & $\begin{array}{l}\text { Correlated } \\
\text { Item-Total } \\
\text { Correlation } \\
\end{array}$ & Keterangan \\
\hline 20 & $\begin{array}{l}\text { Saya merasa tertantang karena koperasi memberikan } \\
\text { kesempatan untuk menyelesaikan sendiri pekerjaan } \\
\text { yang besar }\end{array}$ & 0,795 & Valid \\
\hline 21 & $\begin{array}{l}\text { Saya merasa termotivasi setelah mendapat penghargaan } \\
\text { atau pujian dari pimpinan }\end{array}$ & 0,804 & Valid \\
\hline 22 & $\begin{array}{l}\text { Saya termotivasi karena atasan saya sering } \\
\text { memperhatikan ide (gagasan) saya }\end{array}$ & 0,781 & Valid \\
\hline 23 & $\begin{array}{l}\text { Saya merasa pekerjaan saya memberi saya peluang } \\
\text { untuk berkembang dan menggunakan keahlian yang } \\
\text { dimiliki }\end{array}$ & 0,663 & Valid \\
\hline 24 & $\begin{array}{l}\text { Saya berupaya menyelesaikan pekerjaan dengan } \\
\text { maksimal dan tepat waktu }\end{array}$ & 0,656 & Valid \\
\hline 25 & $\begin{array}{l}\text { Saya memiliki dorongan yang kuat untuk bekerja lebih } \\
\text { keras untuk mencapai tujuan koperasi }\end{array}$ & 0,814 & Valid \\
\hline 26 & $\begin{array}{l}\text { Saya bersedia menerima sanksi apabila secara nyata } \\
\text { melakukan kesalahan dan bersedia untuk } \\
\text { memperbaikinya }\end{array}$ & 0,381 & Valid \\
\hline 27 & $\begin{array}{l}\text { Saya memiliki kesetiaan (loyalitas) yang tinggi pada } \\
\text { koperasi }\end{array}$ & 0,756 & Valid \\
\hline 28 & $\begin{array}{l}\text { Saya bersedia mengikuti pelatihan yang diberikan untuk } \\
\text { peningkatan keterampilan karyawan dalam hal } \\
\text { pengelolaan koperasi dan penerapan financial } \\
\text { technology }\end{array}$ & 0,642 & Valid \\
\hline 29 & $\begin{array}{l}\text { Saya bersedia ditempatkan di kantor cabang lain dalam } \\
\text { rangka perkembangan koperasi }\end{array}$ & 0,880 & Valid \\
\hline 30 & $\begin{array}{l}\text { Saya memiliki keinginan untuk menggembangkan } \\
\text { layanan financial technology }\end{array}$ & 0,616 & Valid \\
\hline
\end{tabular}

Sumber: Data diolah, 2019

Berdasarkan uji SPSS, maka didapatkan nilai Cronbach's Alpha. Hasil uji reliabilitas data responden pada perspektif pelanggan KSP TEB Artha Mulia yang disajikan pada Tabel 5 .

Tabel 5.

Hasil Uji Reliabilitas Data Responden pada Perspektif Pelanggan

\begin{tabular}{cc}
\hline Croanbach's Alpha & Nof Items \\
\hline 0,897 & 16 \\
\hline Sumber: Data diolah, 2019
\end{tabular}

Hasil uji reliabilitas data responden pada perspektif pembelajaran dan pertumbuhan KSP TEB Artha Mulia KSP TEB Artha Mulia yang disajikan pada Tabel 6. 
Tabel 6.

Hasil Uji Reliabilitas Data Responden pada Perspektif Pembelajaran dan Pertumbuhan

\begin{tabular}{cc}
\hline Croanbach's Alpha & Nof Items \\
\hline 0,971 & 30 \\
\hline Sumber: Data diolah, 2019
\end{tabular}

Berdasarkan uji yang telah dilakukan, dapat disimpulkan bahwa instrumen yang digunakan dalam penelitian adalah valid dan reliabel. Ini ditunjukkan dari hasil uji validitas data responden dengan Correlated Item-Total Correlation yang bernilai lebih dari 0,30 dan hasil uji reliabilitas data responden dengan Croanbach's Alpha yang bernilai lebih dari 0,70.

Analisis pengukuran kinerja KSP TEB Artha Mulia pada perspektif keuangan dengan menggunakan rasio-rasio keuangan. Hasil perhitungan rasio keuangan pada KSP TEB Artha Mulia disajikan pada Tabel 7.

Tabel 7.

Hasil Perhitungan Rasio Keuangan KSP TEB Artha Mulia

\begin{tabular}{cccc}
\hline Tahun & Rasio Kas (\%) & $\begin{array}{c}\text { Rasio Kecukupan } \\
\text { Modal Sendiri (\%) }\end{array}$ & $\begin{array}{c}\text { Rasio Rentabilitas Modal } \\
\text { Sendiri (\%) }\end{array}$ \\
\hline 2014 & 16,08 & 18,64 & 2,32 \\
2015 & 18,27 & 20,34 & 1,04 \\
2016 & 18,40 & 16,21 & 3,69 \\
2017 & 10,52 & 14,40 & 4,37 \\
\hline \multicolumn{2}{l}{ Sumber: Data diolah, 2019} & &
\end{tabular}

Tabel 7 menunjukkan bahwa rasio kas dari KSP TEB Artha Mulia pada tahun 2014 - 2016 belum mencapai standar ideal yang ditetapkan, sedangkan pada tahun 2017 telah mencapai standar ideal yang ditetapkan yaitu 10 - 15 persen. Hasil tersebut menunjukkan bahwa KSP TEB Artha Mulia dapat memenuhi kewajiban jangka pendeknya dengan menggunakan kas dan bank yang dimilikinya dengan baik. Rasio kecukupan modal sendiri dari KSP TEB Artha Mulia pada tahun 2014 - 2017 sudah mencapai standar ideal yang telah 
ditentukan yaitu lebih besar dari 8 persen. Melihat hasil tersebut dapat diketahui bahwa modal sendiri tertimbang yang dimiliki KSP TEB Artha Mulia memiliki kualitas baik dalam menyerap kerugian akibat penurunan aset yang dimilikinya. Rasio rentabilitas modal sendiri belum mencapai standar ideal yang ditetapkan yaitu lebih besar atau sama dengan 5 persen. Pada tahun 2014 - 2016 persentase rasio rentabilitas modal sendiri sangat kecil, namun pada tahun 2017 semakin meningkat. Melihat hasil tersebut dapat diketahui bahwa KSP TEB Artha Mulia dalam memberikan balas jasa kepada anggota yang telah berkontribusi dalam menanamkan modalnya berupa simpanan-simpanan tergolong belum maksimal.

Analisis pengukuran kinerja KSP TEB Artha Mulia pada perspektif pelanggan menggunakan kuesioner yang menggambarkan tingkat kepuasan pelanggan yang dalam hal ini merupakan anggota KSP TEB Artha Mulia. Pernyataan responden pada perspektif pelanggan yang telah dihitung persentase pernyataan positif dan negatifnya yang telah disajikan pada Tabel 8 . 
Tabel 8.

Pernyataan Responden pada Perspektif Pelanggan

\begin{tabular}{|c|c|c|c|c|c|c|c|}
\hline \multirow[t]{2}{*}{ No } & \multirow[t]{2}{*}{ Atribut - atribut Mutu Jasa } & \multicolumn{4}{|c|}{ Alternatif Jawaban } & \multicolumn{2}{|c|}{$\begin{array}{c}\text { Persentase } \\
\text { Pernyataan } \\
\text { Responden }(\%)\end{array}$} \\
\hline & & SS & S & $\mathrm{KS}$ & $\mathrm{TS}$ & Positif & Negatif \\
\hline \multicolumn{8}{|c|}{ Reliability (Keandalan) } \\
\hline 1 & Pertanyaan 1 & 40 & 52 & 2 & 0 & 97,87 & 2,13 \\
\hline 2 & Pertanyaan 2 & 36 & 57 & 1 & 0 & 98,94 & 1,06 \\
\hline 3 & Pertanyaan 3 & 21 & 71 & 2 & 0 & 97,87 & 2,13 \\
\hline 4 & Pertanyaan 4 & 18 & 71 & 5 & 0 & 94,68 & 5,32 \\
\hline \multicolumn{8}{|c|}{ Responsiveness (Cepat Tanggap) } \\
\hline 5 & Pertanyaan 5 & 45 & 48 & 1 & 0 & 98,94 & 1,06 \\
\hline 6 & Pertanyaan 6 & 37 & 54 & 2 & 1 & 96,81 & 3,19 \\
\hline 7 & Pertanyaan 7 & 25 & 59 & 10 & 0 & 89,36 & 10,64 \\
\hline \multicolumn{8}{|c|}{ Assurance (Jaminan) } \\
\hline 8 & Pertanyaan 8 & 47 & 46 & 1 & 0 & 98,94 & 1,06 \\
\hline 9 & Pertanyaan 9 & 33 & 61 & 0 & 0 & 100,00 & 0,00 \\
\hline 10 & Pertanyaan 10 & 23 & 66 & 5 & 0 & 94,68 & 5,32 \\
\hline \multicolumn{8}{|c|}{ Empathy (Empati) } \\
\hline 11 & Pertanyaan 11 & 45 & 47 & 2 & 0 & 97,87 & 2,13 \\
\hline 12 & Pertanyaan 12 & 25 & 66 & 2 & 1 & 96,81 & 3,19 \\
\hline 13 & Pertanyaan 13 & 16 & 70 & 8 & 0 & 91,49 & 8,51 \\
\hline \multicolumn{8}{|c|}{ Tangible (Kasat Mata) } \\
\hline 14 & Pertanyaan 14 & 21 & 68 & 4 & 1 & 94,68 & 5,32 \\
\hline 15 & Pertanyaan 15 & 15 & 66 & 12 & 1 & 86,17 & 13,83 \\
\hline \multirow[t]{2}{*}{16} & Pertanyaan 16 & 26 & 66 & 2 & 0 & 97,87 & 2,13 \\
\hline & Rata-rata & & & & & 95,81 & 4,19 \\
\hline
\end{tabular}

Berdasarkan Tabel 8, dapat diketahui bahwa pernyataan positif yang diberikan responden pada perspektif pelanggan adalah sebesar 95,81 persen atau melebihi 60 persen. Hasil ini menunjukkan kinerja KSP TEB Artha Mulia pada perspektif pelanggan digolongkan pada kualifikasi kinerja baik.

Pada tingkat pertumbuhan anggota dihitung dengan membandingkan jumlah pelanggan tahun sekarang dikurangi jumlah pelanggan tahun lalu dibagi dengan jumlah pelanggan tahun lalu yang dinyatakan dengan persentase. Pelanggan yang dimaksud dalam penelitian ini adalah anggota KSP TEB Artha Mulia. Hasil perhitungan tingkat pertumbuhan anggota KSP TEB Artha Mulia tahun 2014 2017 disajikan pada Tabel 9. 
Tabel 9.

Tingkat Pertumbuhan Anggota KSP TEB Artha Mulia

Tahun 2014 - 2017

\begin{tabular}{cccc}
\hline Tahun & Jumlah anggota & $\begin{array}{c}\text { Peningkatan/ } \\
\text { (Penurunan) }\end{array}$ & $\begin{array}{c}\text { Tingkat pertumbuhan anggota } \\
(\%)\end{array}$ \\
\hline 2014 & 324 & - & - \\
2015 & 647 & 323 & 99,69 \\
2016 & 1.037 & 390 & 60,28 \\
2017 & 1.500 & 463 & 44,65 \\
\hline \multicolumn{2}{l}{ Sumber: Data diolah, 2019} &
\end{tabular}

Berdasarkan data pada Tabel 9 diketahui bahwa jumlah anggota KSP TEB Artha Mulia dari tahun 2014 hingga tahun 2017 selalu mengalami peningkatan. Peningkatan dari tahun 2014 - 2015 sebesar 99,69 persen, tahun 2015 - 2016 meningkat sebesar 60,28 persen, serta pada tahun 2016 - 2017 meningkat sebesar 44,65 persen. Peningkatan tersebut menunjukkan bahwa kinerja KSP TEB Artha Mulia dari perspektif pelanggan yang diproksikan dengan tingkat pertumbuhan anggota adalah baik.

Pada perspektif proses bisnis internal yaitu kapasitas infrastruktur diukur dengan melihat pertumbuhan jumlah aset tetap per tahunnya. Jumlah aset tetap KSP TEB Artha Mulia disajikan pada Tabel 10.

Tabel 10.

Peningkatan atau Penurunan Jumlah Aset Tetap KSP TEB Artha Mulia Tahun 2014 - 2017

\begin{tabular}{cccc}
\hline Tahun & $\begin{array}{c}\text { Jumlah Aset Tetap } \\
\text { (Rupiah) }\end{array}$ & $\begin{array}{c}\text { Peningkatan/ } \\
\text { Penurunan } \\
\text { (Rupiah) }\end{array}$ & $\begin{array}{c}\text { Peningkatan/ } \\
\text { Penurunan }(\%)\end{array}$ \\
\hline 2014 & 81.805 .880 & - & - \\
2015 & 157.647 .380 & 75.841 .500 & 92,71 \\
2016 & 301.127 .882 & 143.480 .502 & 91,01 \\
2017 & 3.257 .112 .882 & 2.955 .985 .000 & 981.64 \\
\hline
\end{tabular}

Sumber: Data diolah, 2019

Berdasarkan Tabel 10 menunjukkan bahwa KSP TEB Artha Mulia pada tahun 2014 - 2017 mengalami peningkatan pada aset tetapnya. Pada tahun 2014 - 
2015 mengalami peningkatan sebesar 92,71 persen, pada tahun 2015 - 2016 mengalami pengingkatan sebesar 91,01 persen, dan pada tahun 2016 - 2017 mengalami peningkatan sebesar 981, 64 persen. Peningkatan tersebut menunjukkan kinerja yang baik dari KSP TEB Artha Mulia dan dikualifikasikan pada peningkatan mutu pelayanan.

Tingkat pertumbuhan inovasi dihitung dengan membagi jumlah produk baru dengan jumlah keseluruhan produk dan dikalikan dengan seratus persen. Jumlah produk KSP TEB Artha Mulia dari tahun 2014 - 2017 disajikan pada Tabel 11.

\section{Tabel 11.}

Jumlah Produk Baru dan Jumlah Keseluruhan Produk KSP TEB Artha Mulia pada Tahun 2014 - 2017

\begin{tabular}{cccc}
\hline Tahun & Jumlah Produk Baru & Total Produk & Rasio (\%) \\
\hline 2014 & - & 6 & 0,00 \\
2015 & 1 & 7 & 14,29 \\
2016 & 1 & 8 & 12,50 \\
2017 & 10 & 18 & 55,56 \\
\hline
\end{tabular}

Sumber: Data diolah, 2019

Tabel 11 menunjukkan bahwa KSP TEB Artha Mulia pada tahun 2014 2017 rutin melakukan peningkatan jumlah produk. KSP TEB Artha Mulia sebagai salah satu jenis koperasi simpan pinjam melakukan pengembangan pada produk simpanan dan pinjaman. Selain itu, produk yang dikembangkan oleh KSP TEB Artha Mulia juga dalam hal kemudahan transaksi anggota melalui layanan financial technology. Peningkatan jumlah produk tersebut menunjukkan bahwa KSP TEB Artha Mulia digolongkan dalam kinerja yang baik.

Analisis pengukuran kinerja KSP TEB Artha Mulia pada perspektif pembelajaran dan pertumbuhan menggunakan tingkat retensi karyawan, tingkat produktivitas karyawan dan kuesioner yang menggambarkan tingkat kepuasan 
karyawan. Hasil perhitungan tingkat retensi karyawan KSP TEB Artha Mulia pada tahun 2014 - 2017 disajikan pada Tabel 12.

Tabel 12.

Hasil Perhitungan Tingkat Retensi Karyawan pada Tahun 2014 - 2017

\begin{tabular}{cccc}
\hline \multirow{2}{*}{ Tahun } & $\begin{array}{c}\text { Jumlah Karyawan } \\
\text { Keluar }\end{array}$ & $\begin{array}{c}\text { Jumlah } \\
\text { Karyawan }\end{array}$ & $\begin{array}{c}\text { Tingkat Retensi Karyawan } \\
(\%)\end{array}$ \\
\hline 2014 & - & 5 & 0,00 \\
2015 & 2 & 9 & 22,22 \\
2016 & 2 & 12 & 16,67 \\
2017 & 3 & 12 & 25,00 \\
\hline
\end{tabular}

Sumber: Data diolah, 2019

Berdasarkan Tabel 12, diketahui bahwa tingkat retensi karyawan KSP TEB Artha Mulia mengalami fluktuasi tiap tahunnya. Pada setiap tahunnya terdapat karyawan yang keluar, namun hal ini juga diimbangi dengan jumlah karyawan yang masuk. Adanya karyawan yang keluar menunjukkan kurangnya kepuasan karyawan terhadap koperasi dan kinerja yang kurang baik dari KSP TEB Artha Mulia dalam mempertahankan karyawannya.

Kinerja perspektif pembelajaran dan pertumbuhan dari tingkat produktivitas karyawan dari tahun 2014 hingga tahun 2017 terus mengalami peningkatan. Perhitungan tingkat produktivitas karyawan disajikan pada Tabel 13.

Tabel 13.

Hasil Perhitungan Tingkat Produktivitas Karyawan pada Tahun 2014 - 2017

\begin{tabular}{cccc}
\hline Tahun & $\begin{array}{c}\text { Jumlah Pendapatan } \\
\text { (dalam Rupiah) }\end{array}$ & $\begin{array}{c}\text { Jumlah } \\
\text { Karyawan }\end{array}$ & $\begin{array}{c}\text { Tingkat Produktivitas } \\
\text { Karyawan }\end{array}$ \\
\hline 2014 & 147.654 .338 & 5 & 29.530 .868 \\
2015 & 500.126 .271 & 9 & 55.569 .586 \\
2016 & 990.249 .777 & 12 & 82.520 .815 \\
2017 & 1.823 .897 .188 & 12 & 151.991 .432 \\
\hline
\end{tabular}

Sumber: Data diolah, 2019

Berdasarkan hasil perhitungan tingkat produktivitas karyawan pada tahun 2014 - 2017, menunjukkan bahwa tingkat produktivitas karyawan mengalami kenaikan tiap tahunnya. Jumlah karyawan meningkat begitu pula dengan 
pendapatan yang diperoleh koperasi. Hasil tersebut menunjukkan kinerja yang baik dari KSP TEB Artha Mulia.

Pada pengukuran tingkat kepuasan karyawan dilakukan dengan menggunakan kuesioner. Penilaian dilakukan dengan melihat pernyataan positif dan negatif. Pernyataan positif dan negatif responden pada perspektif pembelajaran dan pertumbuhan disajikan pada Tabel 14 .

Tabel 14.

Pernyataan Responden pada Perspektif Pembelajaran dan Pertumbuhan

\begin{tabular}{|c|c|c|c|c|c|c|c|}
\hline \multirow[t]{2}{*}{ No } & \multirow[t]{2}{*}{ Atribut - atribut Mutu Jasa } & \multicolumn{4}{|c|}{ Alternatif Jawaban } & \multicolumn{2}{|c|}{$\begin{array}{c}\text { Pernyataan Responden } \\
(\%)\end{array}$} \\
\hline & & SS & $\mathrm{S}$ & KS & TS & Positif & Negatif \\
\hline & Atribut Kepuasan Kerja & & & & & & \\
\hline 1 & Pertanyaan 1 & 2 & 12 & 4 & 2 & 70,00 & 30,00 \\
\hline 2 & Pertanyaan 2 & 2 & 13 & 3 & 3 & 70,00 & 30,00 \\
\hline 3 & Pertanyaan 3 & 2 & 10 & 4 & 4 & 60,00 & 40,00 \\
\hline 4 & Pertanyaan 4 & 2 & 11 & 6 & 1 & 65,00 & 35,00 \\
\hline 5 & Pertanyaan 5 & 2 & 13 & 3 & 2 & 75,00 & 25,00 \\
\hline 6 & Pertanyaan 6 & 3 & 15 & 2 & 0 & 90,00 & 10,00 \\
\hline 7 & Pertanyaan 7 & 2 & 14 & 4 & 0 & 80,00 & 20,00 \\
\hline 8 & Pertanyaan 8 & 2 & 12 & 5 & 1 & 70,00 & 30,00 \\
\hline 9 & Pertanyaan 9 & 2 & 13 & 5 & 0 & 75,00 & 25,00 \\
\hline 10 & Pertanyaan 10 & 3 & 10 & 5 & 2 & 65,00 & 35,00 \\
\hline 11 & Pertanyaan 11 & 2 & 12 & 4 & 2 & 70,00 & 30,00 \\
\hline 12 & Pertanyaan 12 & 5 & 13 & 2 & 0 & 90,00 & 10,00 \\
\hline 13 & Pertanyaan 13 & 6 & 13 & 0 & 1 & 95,00 & 5,00 \\
\hline 14 & Pertanyaan 14 & 5 & 15 & 0 & 0 & 100,00 & 0,00 \\
\hline 15 & Pertanyaan 15 & 5 & 15 & 0 & 0 & 100,00 & 0,00 \\
\hline \multicolumn{8}{|c|}{ Atribut Motivasi Karyawan } \\
\hline 16 & Pertanyaan 16 & 2 & 15 & 1 & 2 & 85,00 & 15,00 \\
\hline 17 & Pertanyaan 17 & 2 & 15 & 2 & 1 & 85,00 & 15,00 \\
\hline 18 & Pertanyaan 18 & 3 & 16 & 1 & 0 & 95,00 & 5,00 \\
\hline 19 & Pertanyaan 19 & 2 & 14 & 2 & 2 & 80,00 & 20,00 \\
\hline 20 & Pertanyaan 20 & 2 & 12 & 3 & 3 & 70,00 & 30,00 \\
\hline 21 & Pertanyaan 21 & 1 & 16 & 1 & 2 & 85,00 & 15,00 \\
\hline 22 & Pertanyaan 22 & 2 & 11 & 6 & 1 & 65,00 & 35,00 \\
\hline 23 & Pertanyaan 23 & 2 & 17 & 1 & 0 & 95,00 & 5,00 \\
\hline 24 & Pertanyaan 24 & 4 & 15 & 1 & 0 & 95,00 & 5,00 \\
\hline 25 & Pertanyaan 25 & 3 & 16 & 0 & 1 & 95,00 & 5,00 \\
\hline 26 & Pertanyaan 26 & 4 & 16 & 0 & 0 & 100,00 & 0,00 \\
\hline 27 & Pertanyaan 27 & 4 & 15 & 1 & 0 & 95,00 & 5,00 \\
\hline 28 & Pertanyaan 28 & 4 & 16 & 0 & 0 & 100,00 & 0,00 \\
\hline 29 & Pertanyaan 29 & 2 & 12 & 5 & 1 & 70,00 & 30,00 \\
\hline \multirow[t]{2}{*}{30} & Pertanyaan 30 & 5 & 15 & 0 & 0 & 100,00 & 0,00 \\
\hline & Rata-rata & & & & & 83,00 & 17,00 \\
\hline
\end{tabular}

Sumber: Data diolah, 2019 
Berdasarkan Tabel 14, diketahui bahwa pernyataan positif responden untuk tingkat kepuasan karyawan pada perspektif pembelajaran dan pertumbuhan adalah sebesar 83,00 persen atau melebihi 60 persen. Hal ini menunjukkan bahwa kinerja KSP TEB Artha Mulia pada perspektif pembelajaran dan pertumbuhan yang diproksikan dengan tingkat kepuasan karyawan digolongkan pada kualifikasi kinerja baik.

Implikasi teoritis hasil penelitian ini adalah dapat diketahui bahwa KSP TEB Artha Mulia kinerjanya sudah baik dari perspektif pelanggan dan perspektif proses bisnis internal. Pada perspektif keuangan dan perspektif pembelajaran dan pertumbuhan beberapa aspek belum tergolong baik. KSP TEB Artha Mulia diharapkan dapat mempertahankan kinerja yang sudah baik dan merencanakan strategi yang tepat di masa mendatang untuk memperbaiki kinerja yang kurang baik. Implikasi teoritis lainnya dari hasil penelitian ini adalah dapat memberikan acuan atau bahan referensi bagi para akademisi yang menggunakan penerapan balanced scorecard dalam pengukuran kinerjanya. Implikasi praktis hasil penelitian ini adalah dengan diketahuinya kinerja KSP TEB Artha Mulia dari keempat perspektif balanced scorecard dapat berkontribusi dalam pengukuran kinerja KSP TEB Artha Mulia, sehingga KSP TEB Artha Mulia dapat menggunakan hasil penelitian ini sebagai acuan untuk merencanakan strategi yang tepat di masa mendatang. 


\section{SIMPULAN}

Berdasarkan hasil penelitian dan pembahasan yang telah dijelaskan, maka simpulan dalam penelitian ini adalah kinerja KSP TEB Artha Mulia pada perspektif keuangan dilihat dari rasio likuiditas pada tahun 2014 - 2016 masih belum mencapai standar ideal yang ditetapkan sedangkan pada tahun 2017 sudah mencapai standar ideal yang ditetapkan. Rasio kecukupan modal sendiri pada tahun 2014 - 2017 sudah mencapai standar ideal yang ditetapkan. Rasio profitabilitas pada tahun 2014 - 2017 belum mencapai standar ideal yang ditetapkan. Kinerja KSP TEB Artha Mulia pada perspektif pelanggan dilihat dari tingkat kepuasan pelanggan dan tingkat pertumbuhan anggotaadalah baik. Kinerja KSP TEB Artha Mulia pada perspektif proses bisnis internal dilihat dari pengukuran kapasitas infrastruktur dan tingkat pertumbuhan inovasi juga tergolong baik. Kinerja KSP TEB Artha Mulia pada perspektif pembelajaran dan pertumbuhan dilihat dari pengukuran tingkat produktifitas karyawan dan tingkat kepuasan karyawan adalah baik. Pada tingkat retensi karyawan, masih terdapat karyawan yang keluar sepanjang tahun 2014 - 2017.

Berdasarkan simpulan di atas, maka saran yang dapat diberikan oleh peneliti yaitu agar KSP TEB Artha Mulia perlu mempertahankan kinerja koperasi yang sudah baik dalam perspektif keuangan, perspektif pelanggan, perspektif proses bisnis internal, serta perspektif pembelajaran dan pertumbuhan. KSP TEB Artha Mulia perlu meningkatkan perolehan Sisa Hasil Usaha (SHU) bagian anggota dan lebih memerhatikan kesejahteraan pegawai. Bagi penelitian selanjutnya agar melakukan penelitian dengan jenis koperasi yang berbeda seperti Koperasi Serba 
Usaha, Koperasi Konsumen, Koperasi Pegawai, maupun jenis koperasi lainnya. Selain berbeda dari jenis koperasi, koperasi yang diteliti juga bisa dengan aset yang lebih besar dan tahun berdiri yang lebih lama.

\section{REFERENSI}

Abofaied, A. (2017). Evaluation of Bank's Performance by Using Balanced Score Card: Practical Study in Libyan Environment. International Journal of Business and Management, 5(1), 1-14.

Al-Hosaini, F. F., \& Sofian, S. (2015). A Review of Balanced Scorecard Framework in Higher Education Institution (HEIs). International Review of Management and Marketing, 5(1), 26-35.

Alannita, N. P., \& Suaryana, I. G. N. A. (2014). Pengaruh Kecanggihan Teknologi Informasi, Partisipasi Manajemen dan Kemampuan Teknik Pemakai Sistem Informasi Akuntansi pada Kinerja Individu. E-Jurnal Akuntansi Universitas Udayana, 6(1), 33-45.

Astuti, N. M. M. P., \& Dharmadiaksa, I. B. (2014). Pengaruh Efektivitas Penerapan Sistem Informasi Akuntansi, Pemanfaatan dan Kesesuaian Tugas pada Kinerja Karyawan. E-Jurnal Akuntansi Universitas Udayanan, 9(2), 373-384.

Ghozali, I. (2016). Aplikasi Analisis Multivariete dengan Program IBM SPSS 23. Semarang: Universitas Diponegoro.

Giannopoulos, G., Holt, A., Khansalar, E., \& Cleanthous, S. (2013). The Use of the Balanced Scorecard in Small Companies. International Journal of Business and Management, 8(14), 1-22.

Hery. (2017). Balanced Scorecard for Business. Jakarta: PT Grasindo.

Ibrahim, M., \& Murtala, S. (2015). The Relevance of Balanced Scorecard as a Technique for Assessing Performance in The Nigerian Banking Industry. European Journal of Business, Economics and Accountancy, 3(4), 71-80.

Indranatha, I. G. N. A. L., \& Suryanawa, I. K. (2013). Pengukuran Kinerja Berbasis Balanced Scorecard Pada Koperasi Serba Usaha Kuta Mimba. EJurnal Akuntansi Universitas Udayanakuntansi Universitas Udayana, 4(3), 451-471. 
Kalmykova, E., \& Ryabova, A. (2016). FinTech Market Development Perspectives. In SHS Web of Conferences (pp. 1-5).

Kaplan, R. S., \& Norton, D. P. (1996). The Balanced Scorecard: Translating Strategy Into Action. Cambridge: Harvard Business School Press.

Karma, K. F. A., Yasa, G. W., \& Ratnadi, N. M. D. (2017). Pengaruh Gaya Kepemimpinan Situasional, Budaya Organisasi dan Motivasi Pada Kinerja Karyawan Di PT Bank Pembangunan Daerah Bali Cabang Badung. E-Jurnal Akuntansi Universitas Udayana, 19(2), 885-915.

Kopecka, N. 2015. The Balanced Scorecard Implementation, Integrated Approach and the Quality of Its Measurement. Procedia Economics and Finance, 25, $59-69$.

Lesakova, L., \& Dubcova, K. (2016). Knowledge and Use of The Balanced Scorecard Method in The Businesses in the Slovak Republic. Procedia Social and Behavioral Sciences, 39-48

Limbu, W. P., \& Sisdyani, E. A. (2016). Evaluasi Kinerja Dinas Pendapatan Daerah Kota Denpasar Berbasis Balanced Scorecard. E-Jurnal Akuntansi Universitas Udayana, 15(3), 1682-1710.

Martello, M., Watson, J. G., \& Fischer, M. J. (2016). Implementing A Balanced Scorecard In A Not-For-Profit Organization. Journal of Business \& Economics Research, 14(3), 61-74.

Meifang, Y., He, D., Xianrong, Z., \& Xiaobo, X. (2018). Impact of payment technology innovations on the traditional financial industry: A focus on China. Technological Forecasting and Social Change, 1-9.

Muzdalifa, I., Rahma, I. A., \& Novalia, B. G. (2018). Peran Fintech dalam Meningkatkan Keuangan Inklusif pada UMKM di Indonesia (Pendekatan Keuangan Syariah). Jurnal Masharif Al-Syariah: Jurnal Ekonomi Dan Perbankan Syariah, 3(1).

Ningsih, C. (2014). Pengaruh Keterlibatan Manajemen dan Teknologi Informasi terhadap Kinerja Organisasi Melalui Transfer Knowledge (Studi Pada Satuan Kerja Badan Pemeriksa Keuangan Republik Indonesia), 23(1), 21-42.

Pebrianata, I. W. G. S., \& Putri, I. G. A. M. asri D. (2014). Analisis Komparasi Kinerja Berbasis Balance Scorecard Pada LPD di Kecamatan Denpasar Timur. E-Jurnal Akuntansi Universitas Udayana, 6(2), 340-354. 
Peraturan Deputi Bidang Pengawasan Kementerian Koperasi dan Usaha Kecil dan Menengah Republik Indonesia Nomor 06/Per/Dep.6/IV/2016 Tentang Pedoman Penilaian Kesehatan Koperasi Simpan Pinjam dan Unit Simpan Pinjam Koperasi. 19 April 2016. Deputi Bidang Pengawasan. Jakarta.

Pika, P. A. T. P., \& Dharmadiaksa, I. B. (2018). Analisis Pengukuran Kinerja Perusahaan dengan Menggunakan Konsep balanced Scorecard pada PT BPR Sari Sedana. E-Jurnal Akuntansi Universitas Udayana, 22(2), 1253-1280.

Prawirasasra, K. P. (2018). Financial Technology in Indonesia: disruptive or Collaborative? Reports on Economics and Finance, 4(2), 83-90.

Putri, I. G. A. P. D., \& Wirasedana, I. W. P. (2015). Analisis Perbandingan Penilaian Kinerja BPR dengan Pendekatan Balanced Scorecard. E-Jurnal Akuntansi Universitas Udayana, 13(1), 1-19.

Ridwan, R., Harun, H., An, Y., \& Fahmid, I. M. (2013). The Impact of the Balanced Scorecard on Corporate Performance: The Case of an Australian Public Sector Enterprise. International Business Research, 6(10), 103-110.

Rismawati, \& Mattalata. (2018). Evaluasi Kinerja: Penilaian Kinerja Atas Dasar Prestasi Kerja Berorientasi ke Depan. Makassar: Celebes Media Perkasa.

Sahiti, A., Sahiti, A., Ahmeti, S., \& Aliu, M. (2016). The Impact of Balanced Scorecard on Improving the Performance and Profitability of the Implementing Companies. Mediterranean Journal of Social Sciences, 7(4), $60-65$.

Sari, A. A. S. S. K., \& Putri, I. G. A. M. A. D. (2014). Perbandingan Kinerja PT. Amanaid dan PT. Enviro Sejahtera Abadi dengan Menggunakan Balanced Scorecard. E-Jurnal Akuntansi Universitas Udayana, 7(2), 357-371.

Sepehrdoust, H. (2018). Impact of Information and Communication Technology and Financial Development on Economic Growth of OPEC Developing Economies. Kasetsart Journal of Social Sciences, 1-6.

Stefanovska, L., \& Soklevski, T. (2014). Benefits of Using Balanced Scorecard in Strategic and Operational Planning. Universal Journal of Management, 2(4), $165-171$.

Surya, L. P. L. S. S. (2014). Analisis Kinerja Berbasis Balanced Scorecard pada Koperasi XYZ. E-Jurnal Akuntansi Universitas Udayana, 8(2), 279-293.

Teja, A. (2017). Indonesian Fintech Business: New Innovations or Foster and Collaborate in Business Ecosystems? The Asian Journal of Technology Management, 10(1), 10-18. 
Undang-Undang Nomor 25 Tahun 1992 Tentang Perkoperasian. 21 Oktober 1992. Lembaran Negara Republik Indonesia Tahun 1992 Nomor 116. Jakarta.

Utama, I. G. B. R. (2016). Pengantar Industri Wisata: Tantangan \& Peluang Bisnis Kreatif. Yogyakarta: Deepublish.

Wiagustini, N. L. P. (2014). Manajemen Keuangan. Denpasar: Udayana University Press.

Zizlavsky, O. (2014). The balanced scorecard: Innovative performance measurement and management control system. Journal of Technology Management and Innovation, 9(3), 210-222. 